\title{
Teacher Trainees' Interpretations of Chemical Stability and Chemical Reactivity
}

\author{
Ruby Hanson \\ University of Education, Winneba, Ghana
}

\begin{abstract}
This paper reveals teacher trainees' overreliance on the octet model. It assesses the nature and possible origins of these conceptions. One hundred and thirty-eight teacher trainees in a teaching university, who were purposely selected, participated in this case study. Instruments used in gathering data were worksheets and focus group interviews. Data obtained were analysed quantitatively and qualitatively. Records of the interviews were transcribed after thematic descriptions. Findings showed that majority of the trainees relied heavily on the full shell concept model, which they imbibed from teachers, and so confused the chemical reactivity framework with that of chemical stability. This led them to pay attention to irrelevant features to the negligence of other authentic reasons in their assigned task. The octet model also led the trainees to reduce the relevant number of propositions that they could have considered as possibilities in differentiating between models. These findings will add to existing knowledge among the science learning community as they are relevant to educators interested in conceptual development and students' learning progressions. Remediation was recommended to enable the trainees to form proper mental models of the concept of chemical stability and its application through innovative constructivist teaching strategies.
\end{abstract}

\section{Introduction}

Chemistry, as a discipline, is found in almost all other science-related programmes and vocations such as nursing, medicine, pharmacy, agronomy, chemical engineering, research and many more. Yet, students shy away from the study of chemistry because of a few basic, but abstract rule-governed principles [1] that must necessarily be well understood for further higher learning. Research shows that students struggle to comprehend how chemical reactions occur, even in laboratory practice settings where they are exposed to tangible substances $[2,3,4,5]$. Helping students to relate among the macroscopic, and tangible properties

of matter, as well as their chemical compositions, and structures at the sub-microscopic levels in a practical manner, is a vital goal in the teaching of chemistry. Students often experience learning challenges when they have to deal with visualisations of these submicroscopic structural models such that they develop alternative conceptions about them, and particulate matter in general. They prefer to live in a world where they can see and feel. Thus, when they have to deal with chemical reactivity, where reacting species cannot really be 'seen' in their microscopic forms, they think of the phenomenon as a situation where species merely undergo changes in their systems to attain 'stability' [6].

Students' perception of 'stability' is one about matter that is at 'rest' and 'chemically inactive' because it has attained a full 'outer shell', 'orbital' or 'configuration'. In other words, a system which is deemed to be 'stable' would not be prone to 'attach' itself or be 'involved' in further chemical reaction. Students perceive the stability of compounds as the need of atoms to fill their 'electron shells'; that is, the full electron shell configuration or octet model [1]. This suggests that teachers must provide opportunities through practice, for learners to acquire scientific knowledge alongside their own activities through purposeful interactive discussions. They must create situations that can enable learners to apply other acquired knowledge to reinforce new knowledge. This would enable them to hold discussions and reflect on their discursive discourses in a minimal corrective and crosscutting environment [7].

Students in the high school exhibit in their answers to questions on chemical stability that chemical species with octet or full outer shell presentations are more stable than those with other configurations. Species with octet presentations actually tend to dominate in discussions that concern molecules, ionic lattices, and metallic lattices [6]. Students therefore extend this idea to believe that species with structures such as $\mathrm{Mg}^{6-}$ and $\mathrm{Na}^{7-}$ all carry the octet and so are stable, without due consideration to feasibility on the basis of thermodynamic requirements. It must be noted that the octet framework has pedagogic values as it could be used to explain how some common alternative conceptions are epistemologically related.

Chemical stability is a concept that describes the tendency of a chemical system to 'resist' change due to its thermodynamic stability. In terms of energy factors, what this implies is that a system will preferably be in its lowest energy state with its 
environment [6]. In such a low energy state, a species could be said to be no longer highly 'reactive'. A system is said to be reactive when it is easily prone to attack by a chemical action, apparently to attain a state of stability. The converse holds true. In other words, that system, which is stable, as indicated earlier, is not easily prone to 'attachment' by a chemical action. Oftentimes, students describe stable electronic structures based on 'full shells' or the 'octet' which may work for them part of the time, a situation that could be described as being within the domains of alternative conceptions. This could fall into the domain of factual misconception. They focus on this limited realisation or comprehension, to the exclusion of other factors that could also contribute to chemical stability and reactivity of chemical compounds [1].

The 'octet' is the core around which students centre chemical processes such as ionisation, electron affinity, chemical bonding [8], compound formation and stability. This tends to affect the way they build mental models of abstract chemical phenomena, such that it subsequently impedes their progression to learning higher chemistry. It has been found, however, that positive or guided interactive constructivist academic engagements during learning processes in the classroom or laboratory, provide the required platform for concept development $[9,10]$.

The constructivist learning theory advocates that learning should be an interaction between new knowledge and pre-existing knowledge. In fact, constructivism often seeks to provide avenues for learners to link their own gained experiences with new and daily issues. This kind of learning exploits contexts that deliberately activate pre-existing knowledge in a new situation so that the urge 'to know' and increase relevance of knowledge is acquired [11], as was employed in this study.

Students' excessive reliance on the octet framework appears to be a global issue as shown by Taber $[1,6]$. Ghanaian student teachers (also referred to as trainees in this study) have over the years also exhibited a dependence on the full shell electron model to explain the stability of given related chemical species in a second-year undergraduate periodic chemistry course [6]. In this course, undergraduate teacher trainees are expected to compare the stabilities of given elements and their corresponding cationic and anionic species. In one instance they have to identify and explain their choice of stable species among related sets/triads such as $\mathrm{S}$, $\mathrm{S}^{2-}$ and $\mathrm{S}^{6+}$ for sulphur species, as well as $\mathrm{Al}, \mathrm{Al}^{5-}$ and $\mathrm{Al}^{3+}$ for the possible stable aluminium species, beside an explanation that involved a reliance on the full shell explanation.

In a recent study, when trainees were asked to carry out such a comparative analysis, with explanations for their choices made, among related species such as $\mathrm{Na}^{7-}$ and $\mathrm{Na}^{+}$as well as $\mathrm{Cl}^{-}$and $\mathrm{Cl}^{7+}$, the trainees chose the more reactive species instead, as the stable forms of the dyads in question. Their reasons for their choices (which were wrong) were that their chosen models (species) presented the octet which had full outer-filled shells. Interestingly, all the duets showed 'full outer shells', an indication that the choices made were not based on scientific deductions. These probing exercises revealed that the trainees identified non-scientific interpretations required more intense investigation so that the root cause of their difficulties could be properly diagnosed and addressed through deconstruction and reconstruction. In this study, Taber's [8] standard classroom resources on chemical stability were adopted to diagnose the trainees' problems.

The use of the standard chemical stability probes was to enable a reliable and valid platform that could allow the researcher to explore and elucidate how trainees could decipher among relative stabilities of related chemical species, with reasons. This study was particularly provoked by the interpretive findings from an earlier study [6] where some undergraduate trainees considered the electron configuration of $\mathrm{Mg}^{6-}$ to be more stable than $\mathrm{Mg}$ because it had an octet structure. They also presumed $\mathrm{Mg}^{6-}$ and $\mathrm{Mg}^{2+}$ to be equally stable. This study therefore sought to carry out an in-depth investigation into teacher trainees' conceptual interpretations of the terms 'chemical stability' and 'chemical reactivity', by identifying gaps in their reasoning structures and providing them with a constructive environment to build sound scientific concepts through repetitive probes.

\section{Methodology}

A convenient intact class comprising of 138 teacher trainees formed the sample for this case study which employed an individual action research approach [13]. This was a whole class study that was to enable the researcher to understand how chemistry teacher trainees understood the concept of "chemical stability'. It was also undertaken to find out the nature of possible misconceptions that the trainees held and their origins. Instruments used to gather data were standard chemical stability probes in the form of worksheets and focus group interviews. Three sets of probes were used in this study. In the first probe, the electronic configuration of chlorine was presented in three different ways, with only one of them being correct. The configuration of chlorine atom in the ground state (2.8.7) was juxtaposed with two excited atoms of different configurations. The next step was to compare the chemical stabilities of any two of the three configurations. The trainees had to say whether one of the two species under comparison was more stable or less stable than the other, with explanation. In other cases, they were required to judge if both species under study were equally stable or not, and assign reasons for their choices. The two other probes (2 and 3) were centred on comparisons about the chemical stability of chlorine atom and two of its 
anions, and then oxygen and two of its anions. In summary, the worksheets were designed as:
i)
Worksheet 1: 1.8.8/2.7.8/2.8.7
ii)
Worksheet $2: \mathrm{Cl} / \mathrm{Cl}^{-} / \mathrm{Cl}^{11-}$
iii)
Worksheet 3: $\mathrm{O} / \mathrm{O}^{-} / \mathrm{O}^{2-}$

Each probe contained various triads of related species. These standard probes were originally designed for learners aged between 14 and 16. However, they have been employed as useful tools in cases where learners lacked the necessary concept skills about the nature of matter. The adopted standard probes [12] were designed to explore how learners judge the relative stability and reactivity of related chemical species. Each trainee worked on a copy of three different kinds of probes (worksheets) for 30 minutes each in two work sessions.

In the first session, the trainees worked on Worksheet 1, which was followed by a class discussion and a focus group interview. Worksheets 2 and 3 were administered in a follow-up (second) work session. Each of these sessions was followed by 30 minutes of whole class discussion and then focus group interviews that had six trainees per group. Since each focus group consisted of six trainees, the total number of groups amounted to 23. Ten groups were randomly selected from the 23 groups in each of the sessions, for a focus group interview which lasted for 10 minutes per group. The interview questions were constructed from trainees' incorrect reasoning answers that were provided in the trainees' worksheets as well as from alternative conceptions that were predominant during the whole class discussions, in order to understand their reasoning structures better.

The interview interaction went on until possible questions that could explicate the distinction between chemical stability and reactivity, and their contextual meanings and applications, were saturated; until no new perspectives were introduced. The trainees' responses to questions were audio recorded. Written responses and transcribed quotes (using the QSRNVIVO9) were analysed to determine trainees' explanations and expressions. Transcripts were first coded, using an open-coding process to characterise the trainees' ideas about the octet and principles that govern it, the major categories that emerged were used to characterise trainees' reasoning about factors that led to stability and the processes involved. Validity checks were initially done by cross-checking recorded statements with interviewees.

\section{Results and discussion}

The teacher trainees' responses ( $R$ ) in part one (first tier) of the worksheet exercises were collated for all the three items under study. Each of the three items had three main propositions to be considered. The propositions for the three items are referred to as
Options, 1, 2 and 3. Each of the options also had three possible answers from which the trainees chose the correct or best answer and an 'I do not know' option that they could fall on if none of the three possible answers was suitable for them. The results obtained from the diagnostic probes are presented in Table 1 as frequencies (f) of trainees' responses.

Table 1. Trainees' Responses in the Chemical Stability Probe

\begin{tabular}{|c|c|c|c|c|c|c|}
\hline $\mathrm{R}$ & Option1 & $\mathrm{f}$ & Option2 & $\mathrm{f}$ & Option3 & $f$ \\
\hline \multirow[t]{5}{*}{1} & $\begin{array}{l}1.8 .8 \text { is } \\
\text { more } \\
\text { stable } \\
\text { than } \\
2,7.8\end{array}$ & 11 & $\begin{array}{l}2.7 .8 \text { is } \\
\text { more } \\
\text { stable } \\
\text { than } \\
2.8 .7\end{array}$ & 36 & $\begin{array}{l}* 2.8 .7 \\
\text { is more } \\
\text { stable } \\
\text { than } \\
1.8 .8\end{array}$ & 92 \\
\hline & $\begin{array}{l}1.8 .8 \\
\text { and } \\
2.7 .8 \\
\text { are } \\
\text { equally } \\
\text { stable }\end{array}$ & 29 & $\begin{array}{l}2.7 .8 \\
\text { and } \\
2,8.7 \\
\text { are } \\
\text { equally } \\
\text { stable }\end{array}$ & 0 & $\begin{array}{l}2.8 .7 \\
\text { and } \\
1.8 .8 \\
\text { are } \\
\text { equally } \\
\text { stable }\end{array}$ & 0 \\
\hline & $\begin{array}{l}* 1.8 .8 \\
\text { is less } \\
\text { stable } \\
\text { than } \\
2.7 .8\end{array}$ & 46 & $\begin{array}{l}* 2.7 .8 \\
\text { is less } \\
\text { stable } \\
\text { than } \\
2.8 .7\end{array}$ & 102 & $\begin{array}{l}2.8 .7 \text { is } \\
\text { less } \\
\text { stable } \\
\text { than } \\
1.8 .8\end{array}$ & 36 \\
\hline & $\begin{array}{l}\text { I do not } \\
\text { know }\end{array}$ & 42 & $\begin{array}{l}1 \text { do not } \\
\text { know }\end{array}$ & 0 & $\begin{array}{l}1 \text { do not } \\
\text { know }\end{array}$ & 0 \\
\hline & $\begin{array}{l}\text { No } \\
\text { attempt }\end{array}$ & 10 & $\begin{array}{l}\text { No } \\
\text { attempt }\end{array}$ & 0 & $\begin{array}{l}\text { No } \\
\text { attempt }\end{array}$ & 10 \\
\hline \multirow[t]{4}{*}{2} & $\begin{array}{l}\mathrm{Cl} \text { is } \\
\text { more } \\
\text { stable } \\
\text { than } \mathrm{Cl}^{-}\end{array}$ & 0 & $\begin{array}{l}{ }^{*} \mathrm{Cl}-\text { is } \\
\text { more } \\
\text { stable } \\
\text { than } \\
\mathrm{Cl}^{11-}\end{array}$ & 79 & $\begin{array}{l}\mathrm{Cl}^{11-} \text { is } \\
\text { more } \\
\text { stable } \\
\text { than } \mathrm{Cl}\end{array}$ & 69 \\
\hline & $\begin{array}{l}\mathrm{Cl} \text { and } \\
\mathrm{Cl}^{-} \text {are } \\
\text { equally } \\
\text { stable }\end{array}$ & 0 & $\begin{array}{l}\mathrm{Cl}-\text { and } \\
\mathrm{Cl}^{11-} \text { are } \\
\text { equally } \\
\text { stable }\end{array}$ & 53 & $\begin{array}{l}\mathrm{Cl}^{11-} \text { and } \\
\mathrm{Cl} \text { are } \\
\text { equally } \\
\text { stable }\end{array}$ & 0 \\
\hline & $\begin{array}{l}{ }^{*} \mathrm{Cl} \text { is } \\
\text { less } \\
\text { stable } \\
\text { than } \mathrm{Cl}^{-}\end{array}$ & 138 & $\begin{array}{l}\mathrm{Cl}^{-} \text {is } \\
\text { less } \\
\text { stable } \\
\text { than } \mathrm{Cl}^{-}\end{array}$ & 6 & $\begin{array}{l}* \mathrm{Cl}^{11-} \text { is } \\
\text { less } \\
\text { stable } \\
\text { than } \mathrm{Cl}\end{array}$ & 69 \\
\hline & $\begin{array}{l}\text { I do not } \\
\text { know }\end{array}$ & 0 & $\begin{array}{l}\text { I do not } \\
\text { know }\end{array}$ & 0 & $\begin{array}{l}\text { I do not } \\
\text { know }\end{array}$ & 0 \\
\hline \multirow[t]{5}{*}{3} & $\begin{array}{l}\mathrm{O} \text { is } \\
\text { more } \\
\text { stable } \\
\text { than } \mathrm{O}^{-}\end{array}$ & 43 & $\begin{array}{l}{ }^{*} \mathrm{O}^{-} \text {is } \\
\text { more } \\
\text { stable } \\
\text { than } \mathrm{O}^{2-}\end{array}$ & 6 & $\begin{array}{l}\mathrm{O}^{2-} \text { is } \\
\text { more } \\
\text { stable } \\
\text { than } \mathrm{O}\end{array}$ & 126 \\
\hline & $\begin{array}{l}\mathrm{O} \text { and } \\
\mathrm{O}^{-} \text {are } \\
\text { equally } \\
\text { stable }\end{array}$ & 0 & $\begin{array}{l}\mathrm{O}^{-} \text {and } \\
\mathrm{O}^{2-} \text { are } \\
\text { equally } \\
\text { stable }\end{array}$ & 0 & $\begin{array}{l}\mathrm{O}^{2-} \text { and } \\
\mathrm{O} \text { are } \\
\text { equally } \\
\text { stable }\end{array}$ & 0 \\
\hline & $\begin{array}{l}* \mathrm{O} \text { is } \\
\text { less } \\
\text { stable } \\
\text { than } \mathrm{O}^{-}\end{array}$ & 73 & $\begin{array}{l}\mathrm{O}^{-} \quad \text { is } \\
\text { less } \\
\text { stable } \\
\text { than } \mathrm{O}^{2-}\end{array}$ & 132 & $\begin{array}{l}* \mathrm{O}^{2-} \text { is } \\
\text { less } \\
\text { stable } \\
\text { than O }\end{array}$ & 6 \\
\hline & $\begin{array}{l}\text { I do not } \\
\text { know }\end{array}$ & 20 & $\begin{array}{l}\text { I do not } \\
\text { know }\end{array}$ & 0 & $\begin{array}{l}\text { I do not } \\
\text { know }\end{array}$ & 0 \\
\hline & $\begin{array}{l}\text { No } \\
\text { attempt }\end{array}$ & 2 & $\begin{array}{l}\text { No } \\
\text { attempt }\end{array}$ & 0 & $\begin{array}{l}\text { No } \\
\text { attempt }\end{array}$ & 6 \\
\hline
\end{tabular}


A general overview of the teacher trainees' choice of answers for the various propositions, as observed from Table 1, showed that they hardly chose the option which said that 'they did not know'; meaning that they were certain their chosen answers were correct. Only about $30 \%$ (42) of the sample claimed that 'they did not know' what option was best in the cases of items 1 (electronic configuration of chlorine), while $14.5 \%$ (20) did not know which answers to choose at all and so made no attempt at a choice. Their reasoning answers for their choices of stable configurations among the given sets were interesting to note. Oftentimes, there was no coordination between the answers chosen and assigned reasons. In item 2, which featured the $\mathrm{Cl}, \mathrm{C}^{--}$and $\mathrm{Cl}^{11-}$ triad, there were no 'I do not know' responses. Neither was there any 'no attempts'. There were, however, six (6) of 'no attempt' in item 3, which showed the related chemical species, $\mathrm{O}, \mathrm{O}^{-}$and $\mathrm{O}^{2-}$. A total of 22 trainees chose the 'I do not know' proposition for the oxygen and its related species $\mathrm{O}^{-}$.

The electron configurations, 1.8 .8 and 2.7.8 violate important chemical principles - the Aufbau principle (which has a connection with Pauli's exclusion principle, in terms of energy factors) and Hund's rule. From Table 1, analysis of responses for item 1 , shows that only 46 of them identified that the configuration 1.8 .8 was less stable than 2.7 .8 , due to impossibilities of filling only one electron in the sorbital and eight electrons in the subsequent orbitals (shells). No reference was made by any of the trainees to violation of the rules required for electron arrangement in atoms. Only five (5) trainees mentioned in their reasoning responses that the first orbital should have contained two electrons and not one and so they could not make a choice. At least, these five trainees showed an idea about the Aufbau principle, though they didn't say so expressively. As many as 42 of the trainees could not figure out a good logical proposition to choose for the observations that they were presented with, while 10 made no choices at all. Their reasons, for 'I don't know', though not properly captioned, could be said to border on similar reasons assigned by the minority (of 5 trainees).

In Option 2, for Item 1, the comparative analysis of stability was between the 2.7.8 and 2.8.7 configurations. Here, majority of trainees were able to predict that the 2.7.8 configuration was indeed less stable than the 2.8 .7 configuration. Incidentally, the violation of the Aufbau principle was mentioned by 16 , out of the 102 trainees who made a correct choice. In other cases, the trainees' underlying naïve concept about the full shell stability model influenced their choice of correct answers. This naïve assertion was made on the basis of the fully filled electron shell model as they noted that the middle orbital that showed seven electrons should have been occupied by eight electrons instead only 36 of the trainees opted for the 2.7.8 configuration over the 2.8.7 configuration. In Option 3, where the 2.8.7 configuration was compared with the 1.8.8 configuration, quite a number of the trainees (92) were able to make the correct choice that was proposed. About 36 of them chose the proposition, '2.8.7 is less stable than 1.8.8', which was quite strange, since majority of them (102) were able to make a correct choice of answer in Option 2 and ascribed seemingly correct reasons for their correct choices. In Option 2, 36 trainees chose the option, '2.7.8 is more stable than 2.8.7'. Twenty-three out of these 36 trainees had also chosen a similar wrong proposition in Option 3, 2.8.7 is less stable than 1.8.8'. The interpretation for this observation could be that the affected trainees based their concept of chemical stability on the presence of a fully filled valence orbital, as a few had indicated so in their reasoning sections. The criteria of a full outer shell appeared to be an important driving force than a representation of a species having full inner shell.

The second probe, featured a triad of related chlorine species- $\mathrm{Cl}, \mathrm{Cl}^{-}$and $\mathrm{Cl}^{11-}$. In Option 1 , where the chemical stabilities of $\mathrm{Cl}$ and $\mathrm{Cl}^{-}$were presented in different propositions, all 138 trainees chose, ' $\mathrm{Cl}$ is less stable than $\mathrm{Cl}^{-}$. Again, 79 out of the 138 trainees chose the proposition that said that $\mathrm{Cl}^{-}$was more stable than the $\mathrm{Cl}^{11-}$ ion. That was another interesting revelation with several analytical interpretations. Another 53 intimated that $\mathrm{Cl}^{-}$and $\mathrm{Cl}^{11-}$ were equally stable. Only six chose the proposition that said that $\mathrm{Cl}^{-}$ was less stable than $\mathrm{Cl}^{11-}$. In Option 3, the trainees' choices were divided in two over the propositions. One half (69) correctly noted that $\mathrm{Cl}^{11-}$ was less stable than $\mathrm{Cl}$, while another half (69) chose to say that $\mathrm{Cl}^{11-}$ was more stable than $\mathrm{Cl}$. No trainee chose the 'I do not know' proposition.

Analysis for the oxygen triad showed a similar pattern as that for the chlorine triad. The proposition, ' $\mathrm{O}$ is less stable than $\mathrm{O}^{-}$"was chosen by 73 of the trainees. As many as 20 of them opted for 'I do not know', and 43, for ' $\mathrm{O}$ is more stable than $\mathrm{O}^{-6}$. In Option 2, 132 of the trainees wrongly chose the proposition that $\mathrm{O}^{-}$was less stable than the related $\mathrm{O}^{2-}$ ion. In Option 3, $\mathrm{O}^{2-}$ was noted to be more stable than the $\mathrm{O}$ atom, instead of choosing the best proposition which said that $\mathrm{O}^{2-}$ was less stable than $\mathrm{O}$. Generally, identification of the more stable species in this probe appeared to be more difficult for the trainees than in the other two probes used in this study, and other probes that had been employed in the past. In the case of this latter probe on the oxygen atom and its related ions, it was only in the first option that about half of the trainees made correct options. In the other two options, only a handful (6/138) six out of the trainees appeared to understand the concept.

The trainees generally perceived reactive species to be equally stable simply because, they observed such species to possess eight electrons in their outermost shells. An interpretation of these consistent observations indicate that the trainees' conceptions were pre-conceived notions and conceptual misunderstanding. To confirm this, quite often, the 
intimated that species with full shell electrons displayed the octet, and so they were no longer reactive. They assumed that the neutral atoms that did not possess full outer shells had to lose electrons in order to be stable, or gain several more electrons to attain the octet or fully filled shells, as was observed in $\mathrm{Cl}^{11-}$, for the attainment of stability. In the same way, the oxygen atom was presumed to gain greater stability by two more electrons to attain stability or lose its outer 6 electrons to attain the duet configuration, which spelt stability. Again, no tangible reasons were assigned for choices or assertions made. In other similar studies by Taber [1], similar responses were provided by students in the United Kingdom. Quite a high percentage of Taber's participants $(13 / 16)$ thought that $\mathrm{Na}^{+}$was more stable than the $\mathrm{Na}$ atom because it had an octet or outer full shell presentation.

The alternative conception about full outer electron shells connoting stability over other factors prevailed in the Ghanaian trainees' choices and reasons in their selection of comparative stable species in the triads provided. Quite often, ionic species were seen to be more stable than their native neutral atoms, without regard to the vast amount of energy that was required in ionising a neutral atom. As with related ions in previous probes, $\mathrm{Cl}^{7+}$ and $\mathrm{Cl}^{-}$ were assumed to be equally stable, perhaps due to their octet presentations. None of the trainees noted that the chlorine atom had an exothermic electron affinity and so the chloride ion could be more stable.

With respect to part two (second tier) of the probe that required trainees to justify their choices in the first part (first tier) of the probe, energy changes that accompanied activities were not considered in the answers that they provided. These observations conformed to those made by Hanson [6], Taber [1] and Hanson, Kwarteng and Antwi [14]. It became apparent in this study that both secondary students and student teachers had similar naïve conceptions about chemical stability and reactivity; an indication of a vicious transfer of misconceptions. The trainees in this and other reviewed studies failed to comprehend that species or models presented were in isolation and so oftentimes the neutral atoms tended to be more stable than their related ions. This also implies that the naïve conceptions about chemical stability are global, as observed from other similar earlier studies $[2,1,5]$. There was a confusion over the use of the terms 'stability' and 'reactivity'. Learners considered stability in terms of location of species on the periodic table, intensity of electrical charge, but mostly on the attainment of the octet or fully filled shells.

In the second tier (part) of the probe, some of the trainees' responses to the choices that they made about the triad electronic configurations of chlorine indicated that they had little understanding about the principles that governed how electrons were placed into various orbitals or shells. They displayed inadequate understanding about 'quanta' and energy levels. For example, they intimated that the K-shell in the configuration 2.7.8 was fully filled with electrons but the 1.8 .8 configuration did not have a full $\mathrm{K}$-shell so could not be stable. If this trainee's interpretation of stability was the full shell concept, then he failed to observe that in the 2.7.8 configuration, the second shell was also not full. Thus, not particular pattern for discrimination was employed and subsequently implied that no proper cognitive reasoning pattern was followed in this instance. Several of such observations were made. This, again confirms the observation that the nature and origins of the trainees' wrong observations were close to factual misconceptions, but more of pre-conceived notions and conceptual misunderstanding. Some trainees also noted that the first shell in the 1.8 .8 configuration was not full and suggested instability but the 2.7.8 presentation, though incomplete in the L-shell, had tow full shell, the first and third shells. This was a highly deficient answer also as the 1.8 .8 configuration also had two full shells. Again, there was no scientific basis for these trainees' observations. Other comparisons showed reasons such as: 2.7.8 is more stable than 2.8 .7 because the 2.7 .8 will not bond again but the 2.8 .7 will have to be in a bond to be stable. A few also intimated that they all do not have 'real octets' and so cannot be stable. No further explanation was given for the 'real octets'. Only half (23) of the 46 (out of 138) trainees gave seemingly correct responses such as, "in the 2.7 .8 configuration, an electron has been excited to move from the second shell to the third shell which has higher energy and this makes it more unstable than the 2.8.7".

The underlying conceptual reasoning answers to the second probe was no different from the interpretations gained in the first probe. In this probe the triad showed chlorine atom and chloride ions with different designations $\left(\mathrm{Cl}^{-}\right.$and $\left.\mathrm{Cl}^{11-}\right)$. About half of the sample (69/138) said that a gain of 11 more electrons in the $\mathrm{Cl}^{11-}$ presentation for the system to have 18 electrons in its outermost shell meant more stability for the $\mathrm{Cl}^{11-}$ species, over the $\mathrm{Cl}^{-}$species and still more stable than the $\mathrm{Cl}$ atom. A few others intimated that both the $\mathrm{Cl}^{-}$and $\mathrm{Cl}^{11-}$ were equally stable because they all presented fully filled outermost shells and obeyed the octet rule. They intimated that the $\mathrm{Cl}$ was less stable as it was one electron short of stability. However, $\mathrm{Cl}^{11-}$ would be very inert because of its 18 electrons which follows the 2.8.18 configuration for the K, L, M energy levels. One other common, but wrong response, in support of the 18-electron shell presentation was "the octet rule says that 8 or 18 electrons connote stability". Again, the full shell model was applied wrongly.

A brief discussion resulted in the awareness that chlorine had an exothermic electron affinity and so the chloride ion was considered to be more stable. The chloride ion $\left(\mathrm{Cl}^{-}\right)$was still going to be less reactive (more stable) than the $\mathrm{Cl}^{11-}$ ion because its disposition 
meant higher reactivity and unattainable energy for that configuration to be attained.

The last probe that challenged their understanding about stable oxygen species appeared to be quite difficult for the trainees to work on. Six trainees did not make any attempt at all to respond to the probe.

Interview questions were directed so as to place the problem in context in order that the terms 'stability' and 'reactivity' could be applied correctly by trainees. They were shown models of neutral atoms and anions in dynamic equilibrium. Portions of the focus discussion sessions are presented below.

Tr: Look at the given equation (equation shown) with the species $O^{-}$and $O$. which of them would you say is stable, and which would be reactive?

Trainee 1: $O^{-}$is almost stable as it is about to complete its octet, but ... O is less stable as it needs two more electrons. As for reactivity...(pauses)...they can all react.

Trainee 2: (chips in) $\mathrm{O}^{-}$will be reactive because it shows that it can react with a positive ion. $O$ will not react. It has no charge.

Tr: What does it mean to say a species is reactive or not?

Trainee 3: If it has a charge, then it can be reactive so that it can react as in ionic compound formation but if it is just neutral like say ' $\mathrm{Na}$ ', 'Ca' and even 'O', then you can't expect much activity.

Tr: Okay. Now, which of these species shown to you would be more reactive? (Tr. Shows $O^{-}$and $\mathrm{O}^{2-}$ )

Trainee 4: Mmmm .... Reactive? (Pauses). I think now $\mathrm{O}^{2-}$ will be more reactive than $\mathrm{O}^{-}$because $\mathrm{O}^{2-}$ is more negatively charged and is stable.

$T r$ : So, does it mean that $\mathrm{O}^{2-}$ is reactive and yet stable?

No response at all came from four of the groups who were asked such a similar question. One group said:

Trainee 5: $O$ will be less stable than $O^{-}$but $O^{2-}$ will be less stable than $\mathrm{O}^{-}$because of energy requirements and repulsion factors.

Trainee 5's answer, showed signs of critical thinking and application of knowledge about energy requirements for the changes that could occur from one state to another.

Tr: Considering the answer from Trainee 5, between the three species, which of them would be most reactive and which would be less reactive?

Trainee 6: Okay .... $\mathrm{O}^{2-}$ will be more reactive even though it shows the octet, and $O$ less reactive.
Tr: Why is $O$ less reactive, even though it hasn't got the octet presentation? And $\mathrm{O}^{2-}$ more reactive?

Trainee 2: Like I said before, $O$ is in a stable and non-reactive state. See, it even has no charge to say it will react, but the other ions will react, even if they show octet or not ...from the equation you gave. The $O^{-}$will resist a second electron coming in and so may be a little stable also but not like neutral $O$. it will also not be too reactive or unstable like $O^{2-}$.

Neutral oxygen atom has an exothermic electron affinity and so the $\mathrm{O}^{-}$ion would be more stable, comparatively. The $\mathrm{O}^{2-}$ ion would be reactive with a higher energy. Therefore, the $\mathrm{O}^{-}$ion, with an endothermic electron affinity would be stable and not reactive.

In order to get the trainees to exhaust their innate naïve perceptions and seeming challenges about chemical stability and reactivity, they were shown other models of neutral atoms that were in equilibrium with their ions so that these concepts could better be reflected upon and analysed scientifically. Quite often, when the equilibrium reaction was presented, the trainees intimated an ion to be more stable than its atom with which it was in equilibrium. They presumed the atom to be more reactive, because it had one electron in its valence shell 'to give away', or it had less electrons than a duet or octet, which was incorrect in the circumstance presented. Several inconsistencies were observed among members in a group. Similar observations had been made by Taber [1]. It became apparent that the trainees failed to acknowledge that electrical attraction would lead to the formation of an atom, in the problem that was presented; a case of conceptual misunderstanding. They also failed to see that ionisation was not a spontaneous process and that energy could be required in its formation. If chemistry students can understand this fact, then it would help them to judge species that are stable and ones that are reactive within given contexts.

In a follow up probe, possible configurations of sulphur and fluorine were shown to them to choose the stable species with reasons. The electron configurations for fluorine were: 2.7 and 1.8, while those for sulphur were 1.8.7, 1.7.8, 2.6.8, and 2.8.6.in the latter case, a quadriad was assigned. A similar exercise had been assigned in class. They were asked to pick the ion that had the propensity to be more stable and that which would be more reactive with reasons. Majority of the trainees (6/10 groups) said that both configurations for fluorine were equally chemically stable and would exhibit the same degree of intensity of chemical reactivity. The unscientific reasons given were that:

One of the fluorine configurations showed a stable duet while the other showed a full electron valence shell.

In the case of chemical reactivity, the 2.7 configuration which was more stable was said to be 
relatively reactive because it needed to complete its octet. When the configurations for sulphur were presented, almost the same observation as was with the fluorine, were made.

Two (2) out of the ten (10) groups intimated that:

1.8.7 could be more stable than 2.8 .6 as it needed only one electron to complete its octet but 2.8 .6 required two electrons.

The configuration 1.7.8 was deemed to be stable and not reactive.

Further discussions ensued and a typical interaction that happened in one group, but characteristic of all the other groups is presented.

Tr: Between the configuration, 2.6.8 and 2.8.6, which would be more stable?

Trainee 2 (from group 8): 2.6 .8

\section{Trainee 6 (from group 8): 2.8 .6}

Tr: Think your answers over and this time, explain the reasons for choices that you make.

Trainee 4 (from group 8 stands up to register his desire to answer): I will try ....2.6.8 .....The last shell is full so the particles will be at rest and not react. An inert configuration has been obtained.

Tr: Look at the number of electrons in the second shell. ... Are they full? Is it obeying or flouting a chemical principle? Consider the energy of particles in the third shell as well.

All the trainees sit pensively, absorbed in their thoughts.

Trainee 1(from group 8): Oh, I can figure it all out now. 1.7.8 both have incomplete inner shells, which rightly shouldn't be, according to the building up principle. They may both have full shells but there is a deficiency or mistake in filling up of their electrons.

Trainee 5: Yes, yes, Hund's rule and Aufbau principle! Madam, energy will be required to push an electron from the $K$-shell in the 1.7.8 to a higher energy level and that cannot be, as you told us in class. It won't be easy. Therefore the 2.8.6 is more stable because the 2.6.8 also means more energy to push electrons from the second shell to the third shell. It will come back to the second shell.

Trainees 2 and 3: Yes, Yes ... (in unison).

Further questions were asked on the reactivity of the same species that were used in the interviews about stability.

The submissions were probed exhaustively in all the groups in order to bring out the trainees' alternative ideas about stability and reactivity and help them to see their deficiencies, so that they could appreciate and accept more scientific and logical explanations. Most of the responses given by the trainees were done without due cognisance of energy changes or requirements that governed these chemical phenomena.

Learners (as was observed in this study) find it difficult to integrate topical ideas properly because quite often the chemistry curricula are segmented [15]. A teacher must find a way of bringing in various chemistry concepts during discussions so that learners come to appreciate that each chemical principle is integrated with, and bears on others. Sevian and Talanquer [7] also noted that students found it difficult to connect across different contexts successfully. They envisage that such a problem could translate into challenges for students when they have to coordinate scientific ideas across programmes such as organic, physical and inorganic chemistry.

The objective of this study was to examine and elucidate teacher trainees' understanding, interpretation, and application of the terms 'chemical stability' and 'chemical reactivity' in undergraduate chemistry. This study provided meaning for the set objective by identifying gaps in trainees' understanding through their naïve answers. It came to light that the term 'reactivity' was not part of the trainees' reasoning structure. They believed that 'reactivity' cannot be considered in isolation and should occur during chemical reactions. The hypothetical situation presented to them did not fit into any mental models of chemical reactions or the periodicity concepts learned in various courses. It was discovered that, in order for these trainees to understand the desired concept, appropriate learning environments had to be created so that they could no longer confuse 'stability' with 'reactivity' or the concept of octet. The full outer shell model was their criterion for measuring and distinguishing between chemical reactivity and stability; and this seemed more important than an atom having full inner shells.

One observed idiosyncratic challenge among trainees was their inability to consider energy changes that accompany the formation of ions but dwelt on the octet model. The full outer shell model was their criteria for measuring stability, to the neglect of full inner shells. They also failed to consider the fact that electrons could be quantised. Thus, by following these untoward heuristics, they ended up with wrong options of stable and reactive species and assigned equally wrong reasons for their choices. Taber [1] suggests that in order to help learners to appreciate the distinction between stability and reactivity, the word 'react' must be used for macroscopic processes, while the alternative term, 'quantact' is used to describe molecular reactions that occur during a chemical reaction. In this case, the term 'reactivity' would not be assumed when learners unreactive or stable species. 


\section{Conclusion}

It could be concluded from findings obtained in this study that there is a strong adherence to the octet concept without a corresponding application of the governing principles in an equal measure of that adherence. The principles that governed the filling in of electrons in orbitals was disregarded. The trainees in this study were not able to explain the terms 'chemical stability' and 'chemical reactivity' as expected of learners of their calibre in tertiary institutions because of possible over-emphasis of dependence on full electron shell presentations of species connoting chemical stability, regardless of whether endothermic or exothermic process were required for the 8-electron valence shell model. Most of these misconceptions, which had their origins from factual misconceptions, pre-conceived notions, and conceptual misunderstanding, were uncovered in the second tier or reasoning part of the assessment administered to the trainees. By the end of the researcher's interactive engagement with the trainees through whole class discussions and interviews, they were able to explain and correctly apply the desired terms scientifically, using appropriate scientific language. The probe on chemical stability could therefore be said to be useful in enabling trainees to distinguish between the desired terms and apply them in a more authentic way when presented with real chemical processes. The use of familiar chemical species or contexts [11] enabled the trainees to comprehend the new learning environment in a better realistic manner.

\section{Implication}

Reviewed literature clearly indicated that teachers necessarily must challenge students' beliefs that lead them to make wrong assertions about chemical concepts. They must endeavour to provide opportunities for learners to construct meaning through their own experiences as they engage in discussions and reflections with co-learners in a minimal curative environment. Some of these learning activities could be through engaging visual multimedia processes that will enable learners to form vivid models of basic chemical concepts in a generic and broader applicable manner. Engagement with electronic or e-platforms will usher learners into a more enjoyable and acceptable $21^{\text {st }}$ century mode of learning. More importantly, students' understanding of basic chemical concepts could heighten their desire to pursue higher education in chemistry and other chemistry-related courses such as pharmacy, nursing and medicine so that the world's desire to attain a sustainable world, better education, good health for all, and the provision of food and shelter would be achieved through the study of the sciences.

\section{References}

[1] K. Taber, Chemical misconceptions-prevention, diagnosis and cure -Volume 1 Theoretical background, London: Royal Society of Chemistry, 2002a.

[2] N. Valanides, "Primary student teachers' understanding of the particulate nature of matter and its transformations during dissolving," Chemistry Education: Research and Practice in Europe, vol. 1, pp. 249-262, 2000.

[3] V. Taskin and S. Bernholt, "Students' understanding of chemical formula: A review of empirical research," International Journal of Science Education, vol. 36, no. 1, pp. 157-185, 2014.

[4] H. Ozmen, "Turkish primary students' conceptions about the particulate nature of matter," International Journal of Environmental and Science Education, vol. 6, no. 1, pp. 99$121,2011$.

[5] A. K. Bilgin, F. N. Demircioglu Yurukel and N. Yigit, "The effect of a developed REACT strategy on the conceptual understanding of students: Particulate nature of matter," Journal of Turkish Science Education, vol. 14, no. 2, pp. 65-81, 2017.

[6] R. Hanson, "An investigation into teacher trainees' understanding of chemical stability and its implications," in Proceedings of International Conference on Education (CICE-2018), University of Toronto, , Mississauga, Ontario, Canada, 2018.

[7] H. Sevian and V. Talanquer, "Rethinking chemistry: Alearning progression on chemical thinking," Chemistry Education Research and Practice, vol. 15, pp. 10-23, 2014.

[8] R. Hanson, "Unearthing conceptions about types of chemical bonding through the use of tiered worksheets- A case study," International Journal for Cross-Disciplinary Subjects in Education, vol. 8, no. 12, pp. 3112-3122, 2017.

[9] A. Sam, K. Niebert, R. Hanson and C. Aryeetey, "Fusing scientists' conceptual correspondences to improve teaching of metal complex isomerism in higher education- An educational reconstructive process," International Journal of Academic Research and Reflection, vol. 4, no. 1, pp. 54-64, 2016.

[10] R. R. Hake, "Interactive-engagement versus traditional methods: A six-thousand-student survey of mechanics test data for introductory physics course," American Journal of Physics, vol. 66, no. 1, pp. 64-74, 1998.

[11] N. Ultay and M. Calik, "A comparison of different teaching designs of 'acids and bases' subject," Eurasia Journal of Mathematics, Science \& Technology Education, vol. 12, no. 1, pp. 57-86, 2016.

[12] K. Taber, Chemical misconceptions- prevention, diagnosis and cure- Volume II: classroom resource, London: Royal Society of Chemistry, 2002b.

[13] G. S. C. Hine, "The importance of action research in teacher education programmes," Issues in Educational Research, vol. 23, no. 2, pp. 151-163, 2013. 
[14] R. Hanson, T. A. Kwarteng and V. Antwi, "Undergraduate chemistry teacher trainees' understanding of chemical phenomena," European Journal of Basic and Applied Sciences, vol. 2, no. 3, pp. 8-14, 2015.

[15] F. Yan and V. Talanquer, "Students' ideas about how and why chemical reactions happen: Mapping the conceptual landscape," International Journal of Science Education, vol. 37, no. 18, pp. 3066-3092, 2015. 


\section{APPENDIX A: Samples of probes}
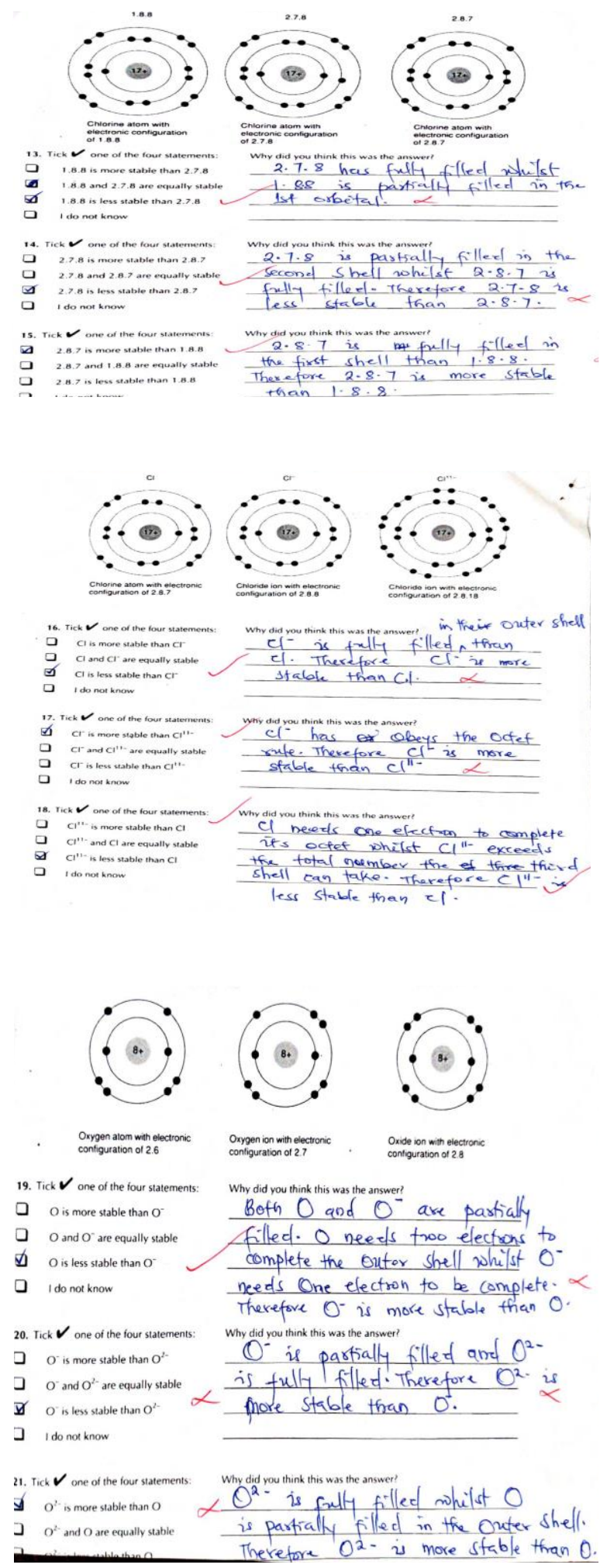
International Journal for Cross-Disciplinary Subjects in Education (IJCDSE), Volume 9, Issue 4, December 2018 